\title{
Factors associated with non-utilization of child immunization in Pakistan: evidence from the Demographic and Health Survey 2006-07
}

\author{
Ayesha Siddiqa Bugvi ${ }^{1}$, Rahla Rahat ${ }^{1}$, Rubeena Zakar ${ }^{1}$, Muhammad Zakria Zakarr ${ }^{1}$ Florian Fischer ${ }^{2 *}$, \\ Muazzam Nasrullah ${ }^{3,4}$ and Riffat Manawar ${ }^{1}$
}

\begin{abstract}
Background: The proportion of incompletely immunized children in Pakistan varies from 37-58\%, and this has recently resulted in outbreaks of measles and polio. The aim of this paper is to determine the factors associated with incomplete immunization among children aged 12-23 months in Pakistan.

Methods: Secondary analysis was conducted on nationally representative cross-sectional survey data from the Pakistan Demographic and Health Survey, 2006-07. The analysis was limited to ever-married mothers who had delivered their last child during the 23 months immediately preceding the survey $(n=2,435)$. 'Complete immunization' was defined as the child having received twelve doses of five vaccines, and 'incomplete immunization' was defined if he/she had missed at least one of these twelve doses. The association between child immunization status and determinants of non-utilization of vaccines was assessed by calculating unadjusted and adjusted odds ratios (AOR) with 95\% confidence intervals using a multivariable binary logistic regression.

Results: The findings of this research showed that nearly $66 \%$ of children were incompletely immunized against seven preventable childhood diseases. The likelihood of incomplete immunization was significantly associated with the father's occupation as a manual worker ( $A O R=1.47 ; 95 \% \mathrm{Cl}: 1.10-1.97$ ), lack of access to information ( $A O R=1.35 ; 95 \%$ $\mathrm{Cl}$ : 1.09-1.66), non-use of antenatal care ( $A O R=1.33 ; 95 \% \mathrm{Cl}: 1.07-1.66)$, children born in Baluchistan region ( $\mathrm{AOR}=1.74$; 95\% Cl: 1.12-2.70) and delivery at home ( $\mathrm{AOR}=1.39 ; 95 \% \mathrm{Cl}: 1.14-1.69)$.

Conclusions: Despite governmental efforts to increase rates of immunization against childhood diseases, the proportion of incompletely immunized children in Pakistan is still high. Targeted interventions are needed to increase the immunization rates in Pakistan. These interventions need to concentrate on people with low socioeconomic and educational status in order to improve their knowledge of this topic.
\end{abstract}

Keywords: Childhood diseases, Immunization, Pakistan, Demographic and Health Survey

\section{Background}

Vaccination is one of the major contributors to public health. It has eliminated some of the most dreaded childhood diseases, such as polio, from all over the world except in a few countries [1]. Childhood immunization is considered to be one of the most important health indicators of a healthy childhood. It assures protection from major childhood diseases, is estimated to prevent millions

\footnotetext{
* Correspondence: f.fischer@uni-bielefeld.de

${ }^{2}$ Department of Public Health Medicine, School of Public Health, Bielefeld University, Bielefeld, Germany

Full list of author information is available at the end of the article
}

of deaths and cases of disability worldwide, and is therefore considered beneficial by the scientific community [2].

In 1974, the World Health Organization (WHO) launched its Expanded Program on Immunization (EPI) with the aim of controlling six childhood diseases: tuberculosis, diphtheria, pertussis (whooping cough), tetanus, polio and measles. Consistent with the WHO's recommendations, Pakistan launched its EPI in 1978 under the guidance of the WHO [3]. Currently, the national EPI aims to immunize all children between the ages of 0 and 23 months against eight vaccine-preventable diseases which include, in addition to the above-mentioned diseases, hepatitis $\mathrm{B}$ 
(vaccine introduced in 2002) and haemophilus influenza type b (Hib) (vaccine introduced in 2008) [3] (Table 1).

In Pakistan, the Health Department provides the immunization schedule for the national EPI in accordance with the WHO guidelines. The EPI is funded by the United Nations International Children's Fund (UNICEF). It is provided free of charge at all state-run health facilities, which are present in every district across Pakistan. Despite having a national immunization program, and a quarterly antipolio campaign, Pakistan is still one of the few countries that is not polio free [4]. The WHO confirmed that in Pakistan there were 198 polio cases in 2011 [5], 58 in 2012 and 83 cases were reported in 2013 [6]. Pakistan has also seen a rise in measles cases in the past couple of years. In 2011, 64 children died, and in 2012 the number increased to 306, with Sindh as the most affected province [7]. It is reported that there were 192 deaths from measles in the Punjab province of Pakistan in 2013 [8].

Although the trends in immunization coverage show improvement for individual doses, especially polio, the percentage of fully immunized children aged 1223 months who have received specific vaccines was only 47.3\% [3]. Many studies have examined the factors that affect immunization rates amongst children. Most of them looked at determinants of utilization of child immunization. Among them, some have looked at individual factors, such as the education, knowledge, attitude and practice of mothers regarding immunization [9-12], while a few focused on structural issues, such as barriers to immunization $[13,14]$.

The benefits of getting a child immunized are hardly questionable, yet studies have shown that, in many developing countries, a sizeable number of parents, usually belonging to socioeconomically disadvantaged populations, resist child immunization $[9,13]$. The primary reason for parents not getting their children immunized is the perception that their children will not be infected with certain diseases such as polio, whooping cough and measles. Further, the parents are apprehensive about the side effects of immunization [15]. Due to structural, cultural and economic factors, Pakistan has lower immunization coverage than other countries in the region [4]. To our knowledge, very few studies $[16,17]$ have looked at the determinants

Table 1 Routine immunization schedule in Pakistan

\begin{tabular}{ll}
\hline Age of child & Vaccination \\
\hline At birth & BCG and Polio 0 \\
6 weeks & DPT1 + HBV1 + Polio1 + Hib1 \\
10 weeks & DPT2 + HBV2 + Polio2 + Hib2 \\
14 weeks & DPT3 + HBV3 + Polio3 + Hib3 \\
9 months & Measles \\
Second year of life & Measles \\
\hline
\end{tabular}

Source: Immunization in Pakistan [3]. of non-utilization of child immunization in Pakistan, although some have looked at determinants of utilization of specific vaccines $[14,18,19]$. Our study aims to describe the individual factors associated with incomplete immunization among last-born children aged 12-23 months in Pakistan.

\section{Methods}

Secondary data analysis was conducted on data from the Pakistan Demographic and Health Survey (PDHS) 200607 . The PDHS is a publicly available dataset produced by ORC Macro for the Measure DHS (Demographic and Health Surveys) Project. It is funded by the US Agency for International Development (USAID). The PDHS contains a wide range of health-related information and is considered to be free of systematic bias [20].

The PDHS is the largest household survey conducted in Pakistan. It is comprised of a nationally representative sample of over 95,000 households collected using a stratified two-stage cluster sampling procedure. However, for security and political reasons, some areas, such as Federally Administered Tribal Areas (FATA), Federally Administered National Areas (FANA) and Azad Jammu and Kashmir (AJK), were not part of the survey. Amongst several modules on fertility, nutrition, reproductive health and malaria in the PDHS, one is on child immunization [21]. The detailed methodology of the survey design, data collection and management has been described elsewhere [21].

Our data was limited to mothers with a last-born child (youngest child) between the ages of 12 to 23 months, resulting in a sample size of 2,435 . The reason for the selection of this age group was that, until 2006, the course of basic vaccinations (i.e., 12 doses for seven vaccine-preventable diseases) for children was completed by the age of 9 months. Some previous studies have also used the same age-group for studying the utilization of immunization $[10,11,14]$. We computed the dependent variable, "immunization status" by using twelve doses of 5 vaccines, i.e. polio (4 doses), BCG (1 dose), DPT (3 doses), HBV (3 doses) and measles (1 dose). The data on Haemophilus influenza type $\mathrm{b}$ (Hib) vaccination were not available in the PDHS 2006-07, as it was first introduced in 2008 in the national EPI. Similarly, no information was available on the Measles 2 vaccination, as it was added to the routine immunization schedule in Pakistan in 2012.

We selected twelve variables, which showed "Received: BCG, polio $(0,1,2,3)$, DPT $(1,2,3)$, HBV $(1,2,3)$ and measles". These variables had five response categories: No, vaccination date on card, reported by mother, vaccination marked on card and DK (don't know). We recoded each variable in a similar way. No and DK responses were recoded as " 0 " and considered as "not received the vaccine", while the other responses "vaccination date on card, reported by mother, vaccination marked on card" were 
recoded as " 1 " and considered as "received the vaccine". Later, we added all twelve vaccine variables and labeled them "Immunization status". The immunization status was recoded as " 0 " if the child had received all twelve doses of the above-mentioned vaccinations and categorized as "complete immunization", and " 1 " if the child had missed one or more vaccinations, and categorized as "incomplete immunization".

We defined "complete immunization" in accordance with the WHO, which considers a child completely immunized if "he or she has received a BCG vaccination against tuberculosis; three doses of DPT vaccine to prevent diphtheria, pertussis, and tetanus (DPT); at least three doses of polio vaccine; and one dose of measles vaccine." Previously published studies have defined "complete immunization" in a similar way $[22,23]$.

Based on a literature review [9-15] and available data within the PDHS 2006-07, 14 independent variables were identified. These were: mother's age, father's age, mother's education, father's education, father's occupation, wealth index (measured on the basis of household assets and ownership of a number of consumer items and divided into quintiles from one [poorest] to five [richest]), sex of child, birth order of child, place of residence, region, access to information, seeking formal advice/treatment, use of antenatal care and place of delivery. The independent variables, such as sex of child, place of residence (urban/ rural) and region (Sindh, Baluchistan, North Western Frontiers Province vs. Punjab [because Punjab is the most developed region having good social indicators]) were used as such. Some independent variables were also recoded, such as mother's and father's age (15-24, 25-34 and $\geq 35$ ), mother's and father's education (no education, up to primary, up to secondary and higher), father's occupation (not working, manual worker, clerical/sales/service and management/professional),wealth index (poor, middle and rich) and birth order of the child (1-3, 4-6 and $\geq 7$ ).

The remaining independent variables were computed and recoded, and limited to categories between two and four because of the small number of cases in some categories. The variable: "seeking formal advice/treatment" was computed using three variables from the PDHS, a) Seek advice/treatment from doctor, b) Seek advice/treatment from Midwife/LHV/nurse and c) Seek advice/treatment from Lady Health Worker (LHW). After computation, the variable was recoded into "0" if the mother has not taken advice/treatment from any of these sources and categorized as "no", and " 1 " if the mother has taken advice from one or more of these sources and categorized as "yes". Similarly, the variable "access to information" was computed and recoded using three variables: a) Access to radio, b) Access to television and c) Access to computer. The data was recoded into " 0 " if the mother has no access to any of these sources and categorized as "no", and " 1 " if the mother had access to one or more of the above-mentioned sources and categorized as "yes".

\section{Statistical analysis}

All the data were weighted and analyzed using SPSS version 17 to account for selection probability, non-response, and sampling differences between regions to produce national estimates of the population. Descriptive statistics for both groups (incomplete immunization and complete immunization) were presented as frequency distributions and percentages. Simple binary logistic regression analysis was carried out to examine the relationship between "incomplete immunization" and the independent variables. In the multiple logistic model, three variables (mother's age, mother's education, wealth quintile) were adjusted and fixed. We entered all the independent variables that were significant at the 0.05 level one by one into the model. We also assessed the multicollinearity between the variables and highly correlated variables were eliminated from the logistical model. Multicollinearity was assessed between mother's and father's age through Pearson correlation and it was significant at the 0.01 level, so the father's age variable was eliminated from the model.

\section{Ethical considerations}

This study is based on secondary analysis of publicly available data; hence no ethical approval was required from our institutions. Permission to use the PDHS2006-07 data was obtained from Measure DHS.

\section{Results}

\section{Individual characteristics and immunization status} of children

The mean age of mothers and fathers was 29.42 (SD \pm 6.49 ) years and 36.99 (SD \pm 10.0 ) years respectively. Two thirds of the selected children $(66 \%)$ were incompletely immunized. The proportion of incompletely immunized was slightly higher among female children (68.6\%) than among male children (64.0\%) (Table 2). Younger (15-24 years) and older ( $\geq 35$ years) mothers had the highest percentages of incompletely immunized children; however, amongst fathers, only the younger group (15-24 years) had the highest percentage of incompletely immunized children (80.8\%). Parents who were illiterate had the highest percentage of incompletely immunized children. Children with higher birth order $(>7)$ were more likely to be incompletely immunized (74.4\%). As far as regional differences were concerned, more than three quarters of children in the province of Baluchistan were incompletely immunized (79.9\%). Lastly, of those children who were delivered at home, $73.6 \%$ were incompletely immunized, and of those born to mothers who had not used antenatal services, $77.2 \%$ were incompletely immunized. 
Table 2 Individual characteristics and immunization status of children aged 12-23 months

\begin{tabular}{|c|c|c|c|}
\hline Variables & Participants (N & 2435) & \\
\hline & Immuniz & ion status & \\
\hline & $\begin{array}{l}\text { Completely } \\
\text { immunized }\end{array}$ & $\begin{array}{l}\text { Incompletely } \\
\text { immunized }\end{array}$ & \\
\hline & $n=825$ & $n=1610$ & \\
\hline & $\mathrm{N}$ (Weighted\%) & N (Weighted\%) & Total \\
\hline
\end{tabular}

\begin{tabular}{llll}
\hline Mother's age (years) & & & \\
$15-24$ & $191(32.4)$ & $398(67.6)$ & 589 \\
$25-34$ & $462(35.4)$ & $843(64.6)$ & 1306 \\
$\geq 35$ & $172(31.7)$ & $369(68.3)$ & 540
\end{tabular}

Father's age (years)

$\begin{array}{llll}15-24 & 34(19.2) & 142(80.8) & 176 \\ 25-34 & 359(35.4) & 655(64.6) & 1014 \\ \geq 35 & 423(34.9) & 790(65.1) & 1213\end{array}$

Mother's education

$\begin{array}{llll}\text { No education } & 397(25.8) & 1138(74.2) & 1535 \\ \text { Up to primary } & 126(36.8) & 218(63.2) & 345 \\ \text { Up to secondary } & 190(50.5) & 186(49.5) & 376 \\ \text { Higher } & 112(62.1) & 68(37.9) & 180\end{array}$

Father's education

No education
Up to primary
Up to secondary
Higher

Father's occupation

$\begin{array}{llll}\text { Not working } & 27(31.8) & 57(68.2) & 84 \\ \text { Manual worker } & 406(28.9) & 997(71.1) & 1403 \\ \text { Clerical/sales/service } & 266(38.5) & 425(61.5) & 691 \\ \text { Management/ } & 125(48.9) & 131(51.1) & 256\end{array}$
professional

\section{Place of residence}

$\begin{array}{llll}\text { Rural } & 436(28.8) & 1076(71.2) & 1512 \\ \text { Urban } & 389(42.2) & 534(57.8) & 923\end{array}$

\section{Sex of child}

Female
Male

\section{Birth order}

$\begin{array}{llll}\geq 7 & 96(25.6) & 280(74.4) & 376 \\ 4-6 & 261(32.6) & 539(67.4) & 800 \\ 1-3 & 468(37.2) & 791(62.8) & 1260 \\ \text { Wealth index } & & & \\ \text { Poor } & 197(19.3) & 824(80.7) & 1021 \\ \text { Middle } & 368(39.7) & 559(60.3) & 927 \\ \text { Rich } & 260(53.4) & 227(46.6) & 487\end{array}$

$\begin{array}{lll}348(31.4) & 761(68.6) & 1109 \\ 477(36.0) & 849(64.0) & 1326\end{array}$$$
260(53.4) \quad 227(46.6)
$$ 
Table 3 Simple Binary logistic regression for the predictors associated with incomplete immunization among children aged 12-23 months

\begin{tabular}{ll}
\hline Variables & Incomplete immunization $P$ value \\
& OR $(95 \% \mathrm{Cl})$
\end{tabular}

Mother's age (years)
$15-24$
$25-34$
$\geq 35$

Father's age (years)

15-24

25-34

$\geq 35$

Mother's education

No education

Up to primary

Up to secondary

Higher

Father's education

No education

Up to primary

Up to secondary

Higher

Father's occupation

Not working
Manual worker
Clerical/sales/service
Management/professional
Place of residence
Rural
Urban

\section{Sex of child}

Female

Male

Birth order

$\geq 7$
$4-6$
$1-3$

Wealth index

$\begin{array}{ll}\text { Poor } & 4.78(3.78-6.06) \\ \text { Middle } & 1.74(1.40-2.18) \\ \text { Rich } & 1\end{array}$

Seek formal advice/treatment

No

Yes
$0.97(0.75-1.24) \quad 0.801$

$0.85(0.68-1.05)$

1

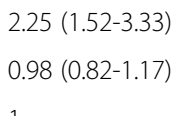

1

$4.71(3.41-6.50)$

$2.82(1.94-4.09)$

$1.61(1.12-2.32)$

1

$3.09(2.41-3.98)$

$2.35(1.75-3.15)$

$1.20(095-1.52)$

1

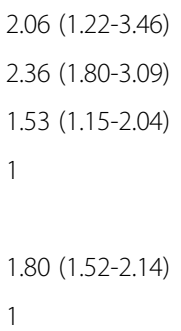

$1.23(1.04-1.46)$

1

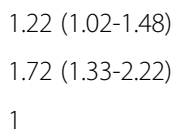

0.035

$<0.001$

$<0.001$

$<0.001$

0.002
Table 3 Simple Binary logistic regression for the predictors associated with incomplete immunization among children aged 12-23 months (Continued)

\begin{tabular}{lll}
\hline Access to information & & \\
No & $2.16(1.79-2.61)$ & $<0.001$ \\
Yes & 1 & \\
Region & $1.52(1.26-1.85)$ & $<0.001$ \\
$\quad$ Sindh & $0.79(0.62-1.01)$ & 0.055 \\
$\quad$ North Western & & \\
Frontier Province & \\
Baluchistan & $2.37(1.55-3.62)$ & $<0.001$ \\
Punjab & 1 & $<0.001$ \\
Place of delivery & & \\
$\quad$ Home & $2.30(1.94-2.74)$ & $<0.001$ \\
Hospital & 1 & \\
Use of antenatal care & & \\
No & $2.18(1.79-2.65)$ & \\
Yes & 1 & \\
\hline
\end{tabular}

Abbreviations: 1, reference category; $\mathrm{OR}$, odds ratio; $\mathrm{Cl}$, confidence interval;

${ }^{\dagger}$ Now called Khyber Pakhtoon Khawa.

children with incomplete immunization (Table 4). Children born in Baluchistan region were 1.7 times more likely to be incompletely immunized (AOR $=1.74 ; 95 \%$ CI: 1.12-2.70) than children born in Punjab. Similarly, the odds of incomplete immunization were high for children born to manual workers (AOR $=1.47 ; 95 \%$ CI: 1.10-1.97) compared to those whose fathers were professionals or had managerial jobs.

\section{Discussion}

Incomplete immunization is one of the major child health issues in Pakistan. Our study found that the children of manual workers were at higher risk of incomplete immunization than the children of relatively better off professionals. As in an earlier study that showed an association between type of maternal occupation (e.g. unskilled workers) and incomplete child immunization [24], it is likely that poorly paid and poorly educated manual workers may not find the time or resources to travel to their nearby health facility for immunization. Additionally, because of parents' poor "health literacy" [25], they may not be able to properly understand the preventive benefits of timely and complete immunization.

Information could play a pivotal role in determining the health behavior of an individual. We found that lack of access to information among mothers increases the likelihood of incomplete immunization for their children. In Pakistan generally, public awareness about immunization, especially among mothers from poor socioeconomic strata, is very low. Therefore, the government of Pakistan dedicates a few days every year to the National Immunization Campaign to 


\section{Table 4 Adjusted odds ratio for multivariable logistic regression of factors independently associated with incomplete immunization among children aged 12-23 months}

\begin{tabular}{|c|c|c|}
\hline Variables & $\begin{array}{l}\text { Incomplete immunization } \\
\text { AOR }(95 \% \mathrm{Cl})\end{array}$ & $P$ value \\
\hline \multicolumn{3}{|l|}{ Father's occupation } \\
\hline Not working & $1.27(0.74-2.19)$ & 0.391 \\
\hline Manual worker & $1.47(1.10-1.97)$ & 0.009 \\
\hline Clerical/sales/service & $1.28(0.94-1.74)$ & 0.112 \\
\hline Management/professional & 1 & \\
\hline \multicolumn{3}{|l|}{ Place of residence } \\
\hline Rural & $0.89(0.72-1.09)$ & 0.262 \\
\hline Urban & 1 & \\
\hline \multicolumn{3}{|l|}{ Birth order } \\
\hline$\geq 7$ & $1.28(0.91-1.82)$ & 0.161 \\
\hline $4-6$ & $1.07(0.85-1.35)$ & 0.554 \\
\hline $1-3$ & 1 & \\
\hline \multicolumn{3}{|l|}{ Seek formal advice/treatment } \\
\hline No & $1.07(0.86-1.33)$ & 0.553 \\
\hline Yes & 1 & \\
\hline \multicolumn{3}{|l|}{ Access to information } \\
\hline No & $1.35(1.09-1.66)$ & 0.006 \\
\hline Yes & 1 & \\
\hline \multicolumn{3}{|l|}{ Region } \\
\hline Sindh & $1.35(1.09-1.65)$ & 0.004 \\
\hline $\begin{array}{l}\text { North Western } \\
\text { Frontier Provincet }\end{array}$ & $0.59(0.46-0.76)$ & $<0.001$ \\
\hline Baluchistan & $1.74(1.12-2.70)$ & 0.014 \\
\hline Punjab & 1 & \\
\hline \multicolumn{3}{|l|}{ Use of antenatal care } \\
\hline No & $1.33(1.07-1.66)$ & 0.009 \\
\hline Yes & 1 & \\
\hline \multicolumn{3}{|l|}{ Place of delivery } \\
\hline Home & $1.39(1.14-1.69)$ & 0.001 \\
\hline Hospital & 1 & \\
\hline
\end{tabular}

Abbreviations: 1, reference category; $\mathrm{AOR}$, adjusted odds ratio; $\mathrm{Cl}$, confidence interval.

A Multivariable logistic regression analysis was carried out to obtain the AOR after controlling for mother's age (continuous variable), mother's education and wealth quintile.

${ }^{\dagger}$ Now called Khyber Pakhtoon Khawa.

increase the level of awareness and motivation about timely completion of the immunization process for children.

Similarly, the level of social development of a region could influence the extent to which parents can avail themselves of preventive health services. Our study showed that region of residence is associated with incomplete immunization. For instance, children in relatively less developed provinces, such as Sindh and Baluchistan, were more likely to have incomplete immunization than those in Punjab, which is more socially and economically developed. Even in North Western Frontier province, now called Khyber Pakhtoon Khawa, complete immunization is much better than other regions because many international organizations such as UNICEF, USAID, the World Bank, UN Women and national organizations such as the Aurat Foundation, PAIMAN and others are working to improve maternal and child health.

Immunization may not be an isolated phenomenon; its timely dispensation is linked with parents' previous interactions with the health-care system [13,24]. For example, if a pregnant mother has antenatal visits, she may get information about immunization and become acquainted with health-care staff. Such acquaintance may be very helpful in getting the child immunized after delivery. Our data also showed that mothers who had infrequent or no antenatal visits had a high probability of incomplete immunization for their children. Similarly, mothers who delivered at home also had a lower chance of complete immunization. The reason could be that the mothers who had home deliveries may have had weaker or no acquaintance with health-care staff and hence were less aware of the importance of the timely completion of vaccination [10].

In patriarchal societies, including Pakistan, a male baby is more valued than a female baby, because males are considered to have economic and social utility in families [26]. However, our study did not find any difference between male and female child immunization status. The reason could be that parents may not be aware of the preventive benefits of immunization. Hence, they may not realize the importance of the completion of immunization for their children regardless of their sex. Although a few studies have found that gender can be a relevant factor in the completion of child immunization [22,27], our analysis did not provide this evidence and it was consistent with other studies which also found no association of child immunization with either sex [24,28].

\section{Limitations}

The above findings ought to be considered in light of certain limitations: Firstly, the analysis was restricted to the last child born during the 23 months immediately preceding the survey; hence, it cannot be generalized to all children under five years of age. Secondly, the analysis conducted cannot establish causal relationships between immunization status and any of the independent variables because of the cross-sectional nature of the survey. Lastly, information on child immunization in the survey is based on either immunization cards or the self-reports of women and the information received through self-reports is subject to recall and social desirability biases. Due to this fact, the completeness of vaccination might be overestimated, because self-reports by the mother were handled in the same way as 
information from vaccination cards. Additionally, a binary categorization (vaccination received vs. not received) was used, which may lead to a loss of information.

\section{Conclusions}

The rate of incomplete immunization of children in Pakistan is alarming. Father's occupation as an unskilled worker, residence in less developed regions such as Baluchistan, lack of access to health information, non-use of antenatal care and home deliveries were found to be independently associated with incomplete immunization of children in Pakistan. Despite limitations, this study shows that EPI services are not reaching the target population and efforts should be made to provide full coverage of vaccination to all children in Pakistan. Therefore, modified interventions are needed to increase the rates of fully immunized children in Pakistan. Additionally, a longitudinal study is needed to explore the factors associated with incomplete immunization levels for each vaccination.

\section{Competing interests}

The authors declare that they have no competing interests.

\section{Authors' contributions}

ASB and RR drafted the initial manuscript. RZ, MZZ and MN supervised and reviewed manuscript writing. $A S B$ and $R R$ contributed in data analysis while RZ supervised data analysis. FF and RM contributed to reviewing final manuscript. All authors have read and approved the final manuscript.

\section{Author details}

${ }^{1}$ Institute of Social and Cultural Studies, University of the Punjab, Lahore, Pakistan. ${ }^{2}$ Department of Public Health Medicine, School of Public Health, Bielefeld University, Bielefeld, Germany. ${ }^{3}$ Rollins School of Public Health, Emory University, Atlanta, Georgia, USA. ${ }^{4}$ Injury Control Research Center, West Virginia University, Morgantown, West Virginia, USA.

Received: 22 October 2013 Accepted: 25 February 2014 Published: 6 March 2014

\section{References}

1. Duclos P, Okwo-Bele J, Gacic-Dobo M, Cherian T: Global immunization: status, progress, challenges and future (Opinion). BMC Int Health Hum Rights 2009, 9(Suppl 1):S2.

2. Bofarraj MAM: Knowledge, attitude and practices of mothers regarding immunization of infants and preschool children at Al-Beida City, Libya. Egypt J Pediatr Allergy Immunol 2011, 9(1):29-34.

3. Masud T, Navaratne KV: The Expanded Program on Immunization inPakistan Recommendations for Improving Performance. Health, Nutrition and Population (HNP) Discussion Paper. Washington, DC: The International Bank for Reconstruction and Development/The World Bank; 2012.

4. World Health Organization: Media Centre Fact sheets Poliomyelitis. World Health Organization; 2013. [http://www.who.int/mediacentre/factsheets/fs114/en/]

5. World Health Organization: Polio Global Emergency Action Plan 2012-2013. Pakistan and Afghanistan: Action to Stop Polio Now In Nigeria; 2012.

6. Expended Program on Immunization. Polio updates. Expended Program on Immunization Govt. of Khyber Pakhtoon Khawa; 2013 [http://www.epikp. gov.pk/polio_updates.php]

7. Pakistan Sees Rise in Measles Cases; 2013 [http://frenchtribune.com/teneur/ 1315227-pakistan-sees-rise-measles-cases]

8. Lahore now measles free-city. Pakistan Today; 2013 [http://www. pakistantoday.com.pk/2013/08/03/city/lahore/lahore-now-measles-free-city/]

9. Torun SD, Bakirci N: Vaccination coverage and reasons for non vaccination in a district of Istanbul. BMC Public Health 2006, 6:125.
10. Jani JV, Schacht CD, Jani IV, Bjune G: Risk factors for incomplete vaccination and missed opportunity for immunization in rural Mozambique. BMC Public Health 2008, 8:161.

11. Tadesse H, Deribew A, Woldie M: Predictors of defaulting from completion of child immunization in south Ethiopia, May 2008 - a case control study. BMC Public Health 2009, 9:150.

12. Owais A, Hanif B, Siddiqui AR, Agha A, Zaidi AKM: Does improving maternal knowledge of vaccines impact infant immunization rates? A community based randomized-controlled trial in Karachi. Pakistan. BMC Public Health 2011, 11:239.

13. Topuzoglu A, Ay P, Hidiroglu S, Gurbuz Y: The barriers against childhood immunizations: a qualitative research among socio-economically disadvantaged mothers. European Journal of Public Health 2007, 17(4):348-352.

14. Cockcroft A, Andersson N, Omer K, Ansari NM, Khan A, Chaudhry UU, Ansari U: One size does not fit all: local determinants of measles vaccination in four districts of Pakistan. BMC Int Health Hum Rights 2009, 9(Suppl 1):S4.

15. Xie J, Dow WH: Longitudinal study of child immunization determinants in China. Social Science \& Medicine 2005, 61:601-611.

16. Mansuri FA, Baig LA: Assessment of immunization service in prerspective of both the recipient and the providers: A reflection from focus group discussions. J Ayub Med Coll Abbottabad 2003, 15(1):14-18.

17. Nisar N, Mirza M, Qadri MH: Knowledge, attitude and practices of mothers regarding immunization of one year old child at Mawatch Goth, Kemari town, Karachi. Pak J Med Sci 2010, 26(1):183-186.

18. Mitchell S, Andersson N, Ansari NM, Omer K, Soberanis JL, Cockcroft A: Equity and vaccine uptake: a cross-sectional study of measles vaccination in Lasbela District, Pakistan. BMC Int Health Hum Rights 2009, 9(Suppl 1):S7.

19. Usman HR, Kristensen S, Rahbar MH, Vermund SH, Habib F, Chamot E: Determinants of third dose of diphtheria-tetanus-pertussis (DTP) completion among children who received DTP1 at rural immunization centres in Pakistan: a cohort study. Trop Med Int Health 2009, 15(1):140-147.

20. Rammohan A, Awofeso N, Fernandez RC: Paternal education status significantly influences infants' measles vaccination uptake, independent of maternal education status. BMC Public Health 2012, 12:336.

21. NIPS: Pakistan Demographic and Health Survey 2006-07. Islamabad: National Institute of Population Studies and Macro International Inc; 2008.

22. Rahman M, Obaida-Nasrin S: Factors affecting acceptance of complete immunization coverage of children under five years in rural Bangladesh. Salud pública de méxico 2010, 52(2):134-140.

23. New Sanou A, Simboro S, Kouyate B, Dugas M, Graham J, Bibeau G: Assessment of factors associated with complete immunization coverage in children aged 12-23 months: a cross-sectional study in Nouna district, Burkina Faso. BMC Int Health Hum Rights 2009, 9(Suppl 1):S10.

24. Antai D: Inequitable childhood immunization uptake in Nigeria: a multilevel analysis of individual and contextual determinants. BMC Infectious Disease 2009, 9:181.

25. Sykes S, Wills J, Rowlands G, Popple K: Understanding critical health literacy: a concept analysis. BMC Public Health 2013, 13:150.

26. Nasrullah M, Bhatti JA: Gender Inequalities and Poor Health Outcomes in Pakistan: A Need of Priority for National Health Research Agenda. J Coll Physicians Surg 2012, 22(5):273-74.

27. Rohini P: Selective Gender Differences in Childhood Nutrition and Immunization in Rural India: The Role of Siblings. Demography 2003, 40(3):395-418.

28. Koller D, Mielck A: Regional and social differences concerning overweight, participation in health check-ups and vaccination. Analysis of data from a whole birth cohort of 6-year old children in a prosperous German city. BMC Public Health 2009, 9:43.

doi:10.1186/1471-2458-14-232

Cite this article as: Bugvi et al:: Factors associated with non-utilization of child immunization in Pakistan: evidence from the Demographic and Health Survey 2006-07. BMC Public Health 2014 14:232. 